\title{
Effects of Uniform and Gradient High Magnetic Fields on Gravity Segregation in Aluminum Alloys
}

\author{
Qiang WANG, ${ }^{1)}$ Changsheng LOU, ${ }^{1,2)}$ Tie LIU, ${ }^{1)}$ Xuejun PANG, ${ }^{1)}$ Keiji NAKAJIMA ${ }^{3)}$ and Jicheng HE ${ }^{1)}$ \\ 1) Key Laboratory of Electromagnetic Processing of Materials (Ministry of Education), Northeastern University, Shenyang \\ China. E-mail: wangq@epm.neu.edu.cn 2) Material Science and Engineering College, Shenyang Ligong University, \\ Shenyang China. $\quad 3$ ) Division of Applied Process Metallurgy, Department of Materials Science and Engineering, Royal \\ Institute of Technology (KTH), SE-100 44 Stockholm, Sweden.
}

(Received on November 26, 2008; accepted on February 26, 2009)

\begin{abstract}
The effects of uniform and gradient magnetic fields on gravity segregation in $\mathrm{Al}-5 \mathrm{wt} \% \mathrm{Cu}$ and Al-10wt\% Mg alloys are investigated. The results show that high magnetic fields can be used to control the solute distribution and thus control gravity segregation caused by the difference of physical properties such as density and magnetic susceptibility between the bulk liquid and the solute-enriched liquid. The effects of the field can be attributed to performances of Lorentz and magnetic forces.
\end{abstract}

KEY WORDS: solidification; metals and alloys; Al alloys; gravity segregation; high magnetic fields.

\section{Introduction}

It is well known that segregation in solidified structure results in poor properties and performances of alloys. For example, core segregation may not only induce the difference in both physical and chemical properties on the scale of grain, but has a great impact upon the mechanical properties of casting on a large area scale as well. Gravity segregation has a detrimental impact on the subsequent processing behavior and properties of cast materials. Therefore, methods for the control of gravity segregation had been constantly pursued, such as solidification under microgravity, ${ }^{1)}$ rapid solidification, ${ }^{2)}$ addition of alloying elements, ${ }^{3)}$ diffusion annealing ${ }^{4)}$ and electromagnetic fields, ${ }^{5,6)}$ etc. However, all these methods have some weaknesses or deficiencies because they are relatively complicated or inefficient.

Nowadays, high magnetic fields have been found to not only largely increase the value of traditional Lorentz force, but also contribute to the likelihood of the use of magnetic force on nonmagnetic materials. ${ }^{7-9)}$ The previous studies show that the high magnetic field can affect the solute distribution during solidification process. ${ }^{8,10-12)}$ Results of experiments using low magnetic fields ${ }^{13}$ and numerical modeling ${ }^{14)}$ indicate that the magnetic field can suppress gravity segregation in term of Lorentz force. The segregation in solidified structure is associated with both the nature of the solute and the magnetic intensity and gradient. The present investigation is undertaken to examine the effects of both uniform and gradient magnetic fields on gravity segregation of solute in $\mathrm{Al}-\mathrm{Cu}$ and $\mathrm{Al}-\mathrm{Mg}$ alloys.

\section{Experimental}

The materials employed in this study are ZL301 Al-Mg alloy and $\mathrm{Al}-5 \mathrm{wt} \% \mathrm{Cu}$ alloy which was prepared from pure aluminum (99.94 wt\%) and copper (99.97 wt\%). The experimental apparatus, as shown in Fig. 1, is based on a superconducting magnet which can generate a magnetic field with a maximum magnetic flux density, $B=12 \mathrm{~T}$ at the centre of a bore of $100 \mathrm{~mm}$ diameter and a maximum value of the product of magnetic flux and its gradient, $B d B / d z=$ $\pm 564 \mathrm{~T}^{2} \mathrm{~m}^{-1}$ at $\pm 105 \mathrm{~mm}$ from the centre of the bore. A resistance furnace (inner diameter $33 \mathrm{~mm}$ ), in which the temperature can reach $1473 \mathrm{~K}$, is installed into the magnet for melting and solidifying the specimens.

For Al-Cu system, a specimen $(9 \mathrm{~mm}$ in diameter and $30 \mathrm{~mm}$ in length) put into an alumina crucible (inner diameter $10 \mathrm{~mm}$; outer diameter $13 \mathrm{~mm}$ ) were heated to $973 \mathrm{~K}$ under an argon atmosphere at a heating rate of $5 \mathrm{~K} \mathrm{~min}^{-1}$

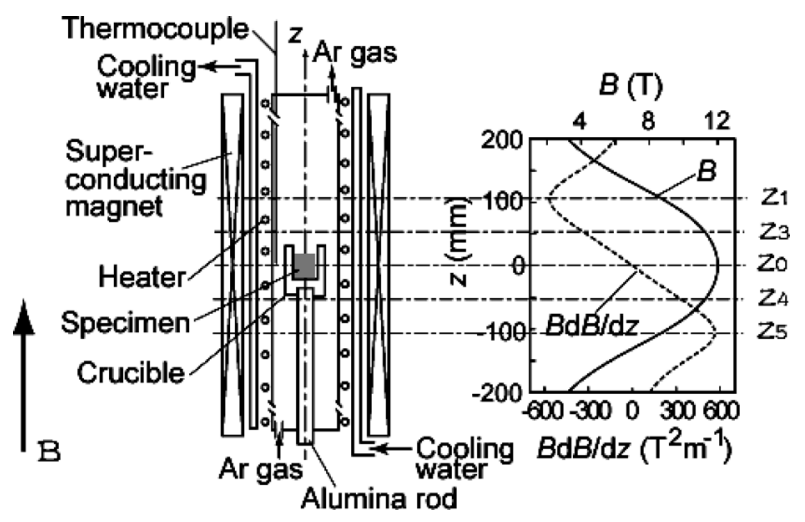

Fig. 1. Schematic illustration of experimental apparatus and distribution of the magnetic field along the bore axis $\left(B_{\max }=12 \mathrm{~T}\right)$. 
and held at the same temperature for $60 \mathrm{~min}$ to ensure its homogeneity. The temperature was then cooled down to $500 \mathrm{~K}$ at a cooling rate of $5 \mathrm{~K} \mathrm{~min}^{-1}$ and finally cooled to room temperature by turning off the DC power source. For $\mathrm{Al}-\mathrm{Mg}$ system, the experimental conditions were the same as the case of $\mathrm{Al}-\mathrm{Cu}$ system, except that the maximum heating temperature was $1023 \mathrm{~K}$. The alloys were also solidified under various high magnetic field conditions. The magnetic field conditions are summarized in Table 1, in which $Z_{0}-Z_{5}$ indicate five positions as shown in Fig. 1 , respectively. The distances between $Z_{1}$ (or $Z_{5}$ ) and $Z_{0}, Z_{3}$ (or

Table 1. Experimental conditions of high magnetic fields.

\begin{tabular}{lc|c}
\hline \multicolumn{2}{l|}{ Magnetic flux density $B, \mathrm{~T}$} & $B \mathrm{~d} B / \mathrm{d} z, \mathrm{~T}^{2} / \mathrm{m}$ \\
\hline $\mathrm{Z}_{0}$ & 0 & - \\
\hline $\mathrm{Z}_{1}$ & \multirow{2}{*}{8.8} & -564 \\
$\mathrm{Z}_{0}$ & 0 \\
$\mathrm{Z}_{5}$ & 564 \\
\hline $\mathrm{Z}_{3}$ & & -282 \\
$\mathrm{Z}_{0}$ & 11.5 & 0 \\
$\mathrm{Z}_{4}$ & & 282 \\
\hline
\end{tabular}

(a)

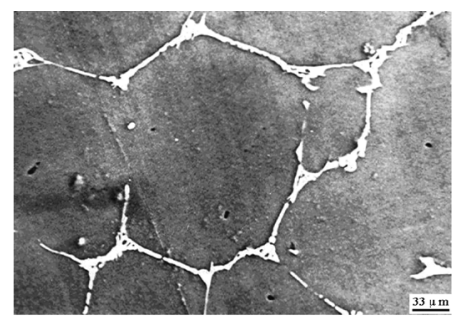

(c)

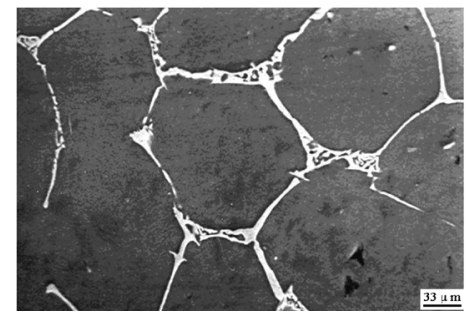

$Z_{4}$ ) and $Z_{0}$ are $105 \mathrm{~mm}$ and $45 \mathrm{~mm}$, respectively. Microstructures of the magnetic field-treated specimens were examined using scanning electron microscopy (SEM) on the longitudinal section. Solute segregation in the specimens was determined using an electron probe microanalysis (EPMA). Each 25 values were measured and averaged separately in the upper and lower parts from the dendrite cores for each specimen. Here, the upper and lower parts are the upside $8 \mathrm{~mm}$ length and the downside $8 \mathrm{~mm}$ length of the specimens, respectively.

\section{Results and Discussion}

Secondary electron photos of $\mathrm{Al}-5 \mathrm{wt} \% \mathrm{Cu}$ and $\mathrm{Al}-$ $10 \mathrm{wt} \% \mathrm{Mg}$ alloys and area distribution images of solutes in these two alloys at $0 \mathrm{~T}$ and $8.8 \mathrm{~T}$ are shown in Fig. 2 and Fig. 3, respectively. At the same time it should be pointed out that some rod-like $\mathrm{Mg}$ poor areas were found at the bottom of Figs. 3(c) and 3(d). These Mg poor phases resulted from the impurity contents in ZL301 alloy. The solidified structures of the alloys all consist of $\alpha$-Al dendritic parti-

(b)

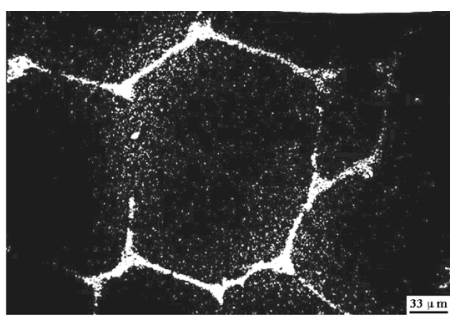

(d)

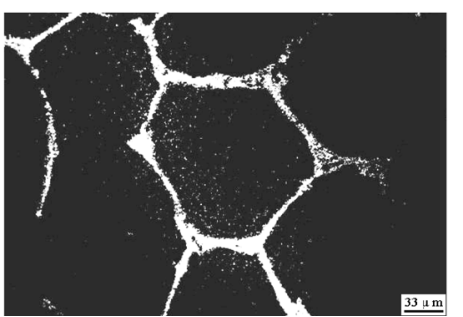

Fig. 2. Secondary electron photos of $\mathrm{Al}-5 \mathrm{wt} \% \mathrm{Cu}$ alloy under a magnetic field of $0 \mathrm{~T}$ (a) and $8.8 \mathrm{~T}$ (c) and corresponding area distribution images of elements (b) and (d).

(a)

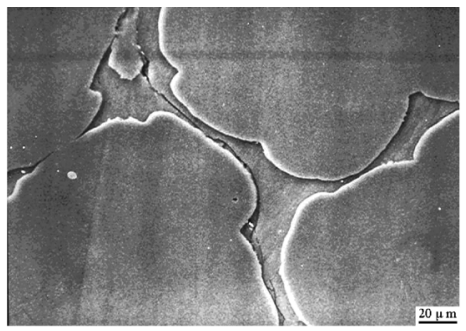

(c)

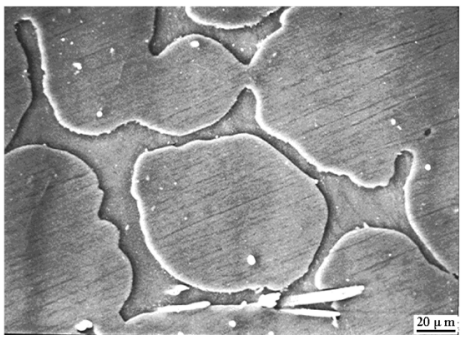

(b)

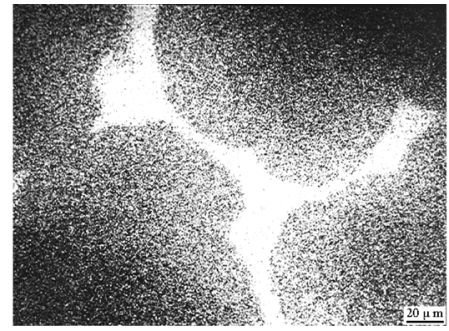

(d)

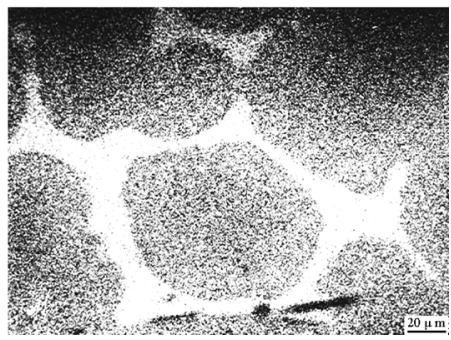

Fig. 3. Secondary electron photos of $\mathrm{Al}-10 \mathrm{wt} \% \mathrm{Mg}$ alloy under a magnetic field of $0 \mathrm{~T}$ (a) and $8.8 \mathrm{~T}$ (c) and corresponding area distribution images of elements (b) and (d). 
cles, with $\alpha+\mathrm{CuAl}_{2}$ eutectic for $\mathrm{Al}-5 \mathrm{wt} \% \mathrm{Cu}$ and $\mathrm{Al}_{3} \mathrm{Mg}_{2}$ for $\mathrm{Al}-10 \mathrm{wt} \% \mathrm{Mg}$ being distributed at the grain boundaries based on the measurement results of EPMA. During dendrite growth, solidification involves solute redistribution and this causes microsegregation. From Fig. 2 and Fig. 3, it can be found that the application of a high magnetic field has no effect on the microsegregation type in these two alloys. The solutes of $\mathrm{Cu}$ and $\mathrm{Mg}$ for $\mathrm{Al}-\mathrm{Cu}$ and $\mathrm{Al}-\mathrm{Mg}$ alloys, respectively, still segregate at the interdendritic regions, although the extent of segregation may be enhanced or reduced by a high magnetic field as mentioned in previous paper. ${ }^{12)}$

In order to evaluate the gravity segregation of the solute in the alloys, an estimate of the extent of segregation can be made by $C_{\mathrm{u}}-C_{1}$, where $C_{\mathrm{u}}$ and $C_{1}$ are the average elemental concentrations at the dendrite cores in the upper and lower parts of the specimens, respectively. The measurement for the mean average composition of dendrite cores is given in Ref. 12).

Figure 4 shows the changes of $C_{\mathrm{u}}-C_{1}$ of solutes in $\mathrm{Al}-5 \mathrm{wt} \% \mathrm{Cu}$ and $\mathrm{Al}-10 \mathrm{wt} \% \mathrm{Mg}$ alloys as a function of $B$, respectively. The negative or positive values in the figures indicate that the elemental concentrations in the dendrite cores in the upper part of the specimen are less or larger than those in the lower part. Gravity segregation mainly results from the movement of liquid, especially from the convection for $\mathrm{Al}-\mathrm{Cu}$ and $\mathrm{Al}-\mathrm{Mg}$ alloys which is linked to the difference in density between the bulk liquid and the soluteenriched liquid. From Fig. 4, Gravity segregation of solute for both alloys without the magnetic field can be detected obviously. However, with the application of high uniform magnetic field, the value of $C_{\mathrm{u}}-C_{1}$ increases (for $\mathrm{Al}-\mathrm{Cu}$ system) or decreases (for $\mathrm{Al}-\mathrm{Mg}$ system) gradually with increasing $B$ and tend to be zero at $11.5 \mathrm{~T}$. This indicates that the high uniform magnetic field can reduce remarkably the extent of gravity segregation. When a high uniform magnetic field is imposed on an electrically conducting fluid, the interaction of the electric current which is induced by the movement of the fluid and the imposed field will then generate Lorentz force which will suppress significantly fluid flow. Therefore, gravity segregation associated with the liquid movement can be decreased under a high magnetic field because of the braking effect of the field on the convection. ${ }^{8,15)}$

The effects of gradient magnetic fields on gravity segregation of $\mathrm{Al}-5 \mathrm{wt} \% \mathrm{Cu}$ and $\mathrm{Al}-10 \mathrm{wt} \% \mathrm{Mg}$ alloys are shown in Fig. 5. However, in this case, the magnetic flux density $B$ is not constant because of the limits of the experimental apparatus. In other words, the effects of Lorentz force caused by uniform magnetic fields that were mentioned above are also involved in this figure. It can be seen that the values of $C_{\mathrm{u}}-C_{1}$ for both cases are near zero at the gradient $B d B / d z=-564 \mathrm{~T}^{2} \mathrm{~m}^{-1}$. Following these two values, the $C_{\mathrm{u}}-C_{1}$ decreases for $\mathrm{Al}-5 \mathrm{wt} \% \mathrm{Cu}$ or increases for $\mathrm{Al}-10 \mathrm{wt} \% \mathrm{Mg}$ with increasing $B d B / d z$. This indicates that the gravity segregation can be decreased for both $\mathrm{Al}-5 \mathrm{wt} \% \mathrm{Cu}$ and $\mathrm{Al}-10 \mathrm{wt} \% \mathrm{Mg}$ alloys when the value of $B d B / d z$ changes from positive to negative. According to the Helmholtz free energy which is stored in the flow medium by a magnetic field, the electromagnetic forces acting on the fluid are Lorentz force, $\vec{F}_{\mathrm{L}}$ and magnetic force, $\vec{F}_{\mathrm{M}}$. The

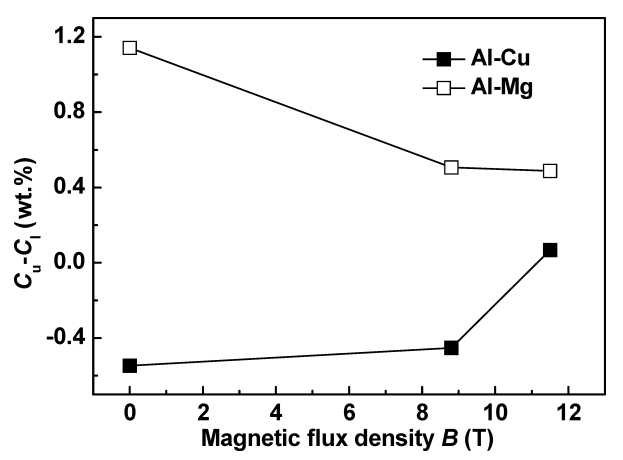

Fig. 4. Changes of $C_{\mathrm{u}}-C_{1}$ of solutes in $\mathrm{Al}-5 \mathrm{wt} \% \mathrm{Cu}$ and $\mathrm{Al}-$ $10 \mathrm{wt} \% \mathrm{Mg}$ alloys as a function of $B$.

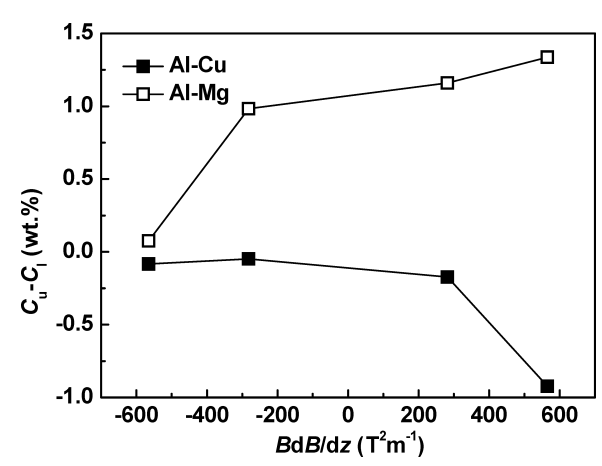

Fig. 5. Changes of $C_{\mathrm{u}}-C_{1}$ of solutes in $\mathrm{Al}-5 \mathrm{wt} \% \mathrm{Cu}$ and $\mathrm{Al}-$ $10 \mathrm{wt} \% \mathrm{Mg}$ alloys as a function of $B d B / d z$.

latter which is only generated at gradient magnetic fields is considered to be able to act on the solute-enriched liquid and given as $F_{\mathrm{M}}=\left(\chi / \mu_{0}\right) V B(d B / d z)$, where $\mu_{0}$ is vacuum magnetic permeability, $\chi$ is the magnetic susceptibility of the solute-enriched liquid and $V$ is the volume of the soluteenriched liquid. However, the exact magnitude of $F_{\mathrm{M}}$ is hard to obtain due to the lack of above parameters. Under a negative field gradient, $\mathrm{Cu}$-enriched liquid will be acted on magnetic force which is upwards to suppress their settlement because of its negative susceptibility. Consequently, gravity segregation resulted mainly from the density difference between bulk liquid and solute-enriched liquid in $\mathrm{Al}-5 \mathrm{wt} \% \mathrm{Cu}$ alloy will be, to some extent, decreased, due to the canceling each other of the magnetic and gravitational force. In the case of positive gradients, the magnetic force acting on $\mathrm{Cu}$-enriched liquid is downwards and this will thus enhance gravity segregation. On the other hand, under a negative field gradient, Mg-enriched liquid will be acted on magnetic force which is downwards to suppress their floatation because of its positive susceptibility. As a result, gravity segregation in $\mathrm{Al}-10 \mathrm{wt} \% \mathrm{Mg}$ alloy will be also enhanced under positive gradients and decreased under negative gradients owing to the density difference and magnetic force.

\section{Conclusions}

An application of uniform magnetic field decreased gravity segregation of solutes in $\mathrm{Al}-5 \mathrm{wt} \% \mathrm{Cu}$ alloy and $\mathrm{Al}-$ $10 \mathrm{wt} \% \mathrm{Mg}$ alloys. Gradient magnetic fields could also decrease gravity segregation in $\mathrm{Al}-5 \mathrm{wt} \% \mathrm{Cu}$ alloy but increase it in $\mathrm{Al}-10 \mathrm{wt} \% \mathrm{Mg}$ alloy. The effects of the field can be at- 
tributed to performances of Lorentz and magnetic force.

\section{Acknowledgement}

This work was supported by the National Natural Science Foundation of China (Grant No. 50374027), the Program for New Century Excellent Talents in University (Grant No. NCET-06-0289) and the 111 project (Grant No. B07015).

\section{REFERENCES}

1) C. W. Lan and C. Y. Tu: J. Cryst. Growth, 237-239 (2002), 1881.

2) M. Nishida, Y. Kawamura and T. Yamamuro: Mater. Sci. Eng. A, 375-377 (2004), 1217.

3) Z. Li, A. M. Samuel, F. H. Samuel and C. Ravidran: J. Mater. Sci., 38 (2003), 1203.

4) J. Loboda-Cackovic: Vacuum, 48 (1997), 913.

5) C. Stelian, Y. Delannoy, Y. Fautrelle and T. Duffar: J. Cryst. Growth, 266 (2004), 207.
6) R. Hermann, G. Behr, G. Gerbeth, J. Priede, H. J. Uhlemann, F. Fischer and L. Schultz: J. Cryst. Growth, 275 (2005), 1533.

7) Q. Wang, E. G. Wang and J. C. He: J. Mater. Sci. Eng., 21 (2003), 590 .

8) S. Asai: Sci. Technol. Adv. Mater., 1 (2000), 191.

9) Y. Yuan, K. Sassa, K. Iwai, Q. Wang, J. C. He and S. Asai: ISIJ Int., 48 (2008), 901.

10) Q. Wang, C. J. Wang and X. J. Pang: Chinese J. Mater. Res., 18 (2004), 568.

11) C. J. Wang, Q. Wang, Y. Q. Wang, J. Huang and J. C. He: Acta Phys. Sin., 55 (2006), 648.

12) Q. Wang, X. J. Pang, C. J. Wang, T. Liu, D. G. Li and J. C. He: Mater. Sci. Forum, 539-543 (2007), 457.

13) P. J. Prescott and F. P. Incropera: ASME J. Heat Transfer, 115 (1993), 302.

14) D. Samanta and N. Zabaras: Int. J. Heat Mass Transfer, 49 (2006), 4850 .

15) B. Ganapathysubramanian and N. Zabaras: Int. J. Heat Mass Transfer, 48 (2005), 4174. 